\title{
Effects of Aging Temperature on Moisture Absorption of Perforated GFRP
}

\author{
Shiva Eslami, Fathollah Taheri-Behrooz, and Farid Taheri \\ Department of Civil and Resource Engineering, Dalhousie University, Halifax, NS, B3H 4R2, Canada \\ Correspondence should be addressed to Farid Taheri, farid.taheri@dal.ca
}

Received 1 November 2011; Revised 12 December 2011; Accepted 12 December 2011

Academic Editor: Luigi Nicolais

Copyright (c) 2012 Shiva Eslami et al. This is an open access article distributed under the Creative Commons Attribution License, which permits unrestricted use, distribution, and reproduction in any medium, provided the original work is properly cited.

This paper examines the effects of aging on the flexural stiffness and bending loading capacity of a perforated glass fiber-reinforced epoxy composite subjected to combined moisture and elevated temperature. Specimens, in the configuration of one-quarter of a perforated GFRP tube, were aged in $60 \%$ humidity and temperatures of 40,60 , and $80^{\circ} \mathrm{C}$, respectively. Moisture absorptions of the specimens were measured during the aging process, and bending tests were conducted on the specimens after aging. The SEM images were also captured to further examine the effects of the moisture absorption on the aged specimens. The results indicated that the increase in the aging temperature reduced the diffusion coefficient, thus inducing more moisture absorption by the composite and in turn causing more reduction in composite's flexural stiffness and bending capacity. Moreover, the ability of Fick's equation for predicting the moisture absorption rate in such perforated thin-walled composite configuration at various moisture contents and temperatures was also assessed. A semiempirical equation was developed and proposed by which the reduction of the stiffness in the perforated aged GFRP structures could be predicted.

\section{Introduction}

Directional wells are one of the most effective and reliable technologies used nowadays in oil and gas industry. Hundreds of directional wells have been installed all over the world to increase access to reservoirs and consequently to increase the productivity and total recovery. From cost perspective, a horizontal well can be more expensive to drill and complete for production in comparison to a vertical well. Therefore, the oil industry requires assurance that a horizontal well would be the most effective and economical option for a given reservoir. One of the challenges often arisen in this field is when one has to replace the so-called "liner" in such wells, usually located often miles under the ground. Liners are conventionally made of perforated steel tubes used to stabilize the directional and vertical wells to access the target producing areas. Annually, hundreds of millions of dollars are spent in replacing the damaged and corroded steel liners in such wells. The concept of replacing steel liners with perforated composite materials such as glass fiber-reinforced plastic (GFRP) has been a novel idea that is postulated to be an effective means for replacing aged steel liners.

In general, fiber-reinforced polymer materials offer better properties in some aspects in comparison to other materials, including superior corrosion resistance, high strength and stiffness to weight ratio, and the ability to be tailored to various configurations. Effective design of components with such materials requires a thorough knowledge of the capabilities and limitations of the constituent materials. Lack of understanding of the behaviors of composites under various conditions has indeed impeded wider development of their applications. Despite the fact that various aspects of the mechanical responses of GFRP have been widely studied, appropriate investigations should be conducted when such materials are to be used in well environment. An important aspect that would require in-depth evaluation in such circumstances would be the influence of the environmental loading conditions (temperature, humidity, etc.) on the structural performance of such composites liners, in order to ensure their long-term reliability, since such liners would 
become in contact with various chemicals during the service life of the oil wells.

It is well known that, for instance, moisture absorption changes the thermophysical and mechanical properties of fiber-reinforced plastics (FRP) in general $[1,2]$. Moisture can cause plasticization and hydrolysis of a polymeric matrix, reducing its glasstransition temperature and affecting the fiber-matrix interface bond, leading to loss of mechanical integrity; this degradation would become more adverse at elevated temperatures [3-6].

In FRP, the fiber-matrix interface is the medium for transferring the applied loads from one fiber to another; hence, it plays an important role in controlling the strength of composites. Previous investigations [7-9] have shown that humidity diffusion through the matrix is accomplished inherently slowly; nonetheless, moisture would diffuse along the fiber/matrix interface more easily and in turn would degrade the interface bond.

Moreover, the inconsistent swelling of the matrix, as a result of moisture absorption, would create undesirable stress concentration regions. Also, in the case of glass fibers, moisture could also cause degradation at the fiber level in fact. In glass fibers, moisture extracts ions from the fiber, causing changes in its structures, leading to further degradation [10]. In addition, the fiber cross-section shape has been found to affect the moisture diffusion rate [11]; for instance, fibers with regular cross-section (like glass fibers) provide more diffusivity in comparison to fibers with arbitrary cross-section (such as most carbon fibers). It has also been commented that glass fibers possess more permeable nature when subjected to moisture in comparison to carbon fibers [11]. There are also other notable studies investigating the aging effects on woven fiber-reinforced composites [12-14]. For example, Nakai et al. [14] studied the degradation of braided glass/epoxy plates in hot water and reported that increasing the exposure time of humidity and temperature would adversely impact the fiber/matrix interface property, first causing degradation at the interface around fiber bundles, but then subsequently, after a long exposure time, the degradation further penetrates inside the fiber bundles.

As stated, several investigations have been conducted examining the effects of moisture and temperature on the mechanical properties of glass/epoxy coupon specimens; however, only a few studies have been documented in consideration of the effect of environmental elements on tubular braided structures. In such cases, although the material may be the same, the manufacturing process, the geometry, and the diffusion surface areas would be different [15]. For instance, in comparing the case of a rectangular coupon specimen with a cylindrically shaped specimen, one realizes that moisture diffuses into the specimen through two surfaces and four edges in the rectangular configuration, while in a tube moisture can penetrate through four areas (two surfaces and two edges). Moreover, in general, humidity penetrates quicker into the specimens through the edges, and then moisture will travel along the fibers. It can be therefore appreciated that the diffusion rate would be greater in a rectangular shape specimen in comparison to a tubular configuration. Moreover, when a tube is perforated, then the edge surface areas associated to the perforations would be larger, thus facilitating higher diffusion rate.

The above observation prompted this study; in order to better understand the diffusion characteristics in perforated configurations, one quarter of a perforated tube will be examined in the present work.

\section{Theoretical Background}

Although it has been shown that the absorption behavior of some polymers is non-Fickian [16], in general, to estimate the amount of moisture intake in a composite whose matrix is epoxy, the use of Fick's model would be admissible. Fick's model was originally developed for determining the amount of moisture absorption in materials (for an infinitely large plate of thickness $h$ ) at a given time $t$. The solution has been given as [17]

$$
\frac{M_{\%}}{M_{\infty}}=1-\frac{8}{\pi^{2}} \sum_{n=0}^{\infty} \frac{1}{(2 n+1)^{2}} \exp \left[-\frac{D(2 n+1)^{2} \pi^{2} t}{h^{2}}\right] .
$$

Or after some manipulations, the above can be represented in the following form:

$$
\frac{M_{\%}}{M_{\infty}} \approx 1-\exp \left[-7.3\left(\frac{D t}{h^{2}}\right)^{0.75}\right],
$$

where $M_{\%}$ is the percent moisture absorbed at the time $t$, $M_{\infty}$ is the percent moisture absorbed at saturation, $h$ is the specimen thickness, and $D$ is the diffusion coefficient.

It should be noted that admissibility of the use of the above equation for estimating moisture absorption in tubular FRP specimens has been examined and confirmed by several researchers (see, e.g., references $[15,18]$ ).

By plotting the graph of moisture content versus time, one can calculate the magnitude of $D$ through the slope of the linear portion of the curve; mathematically, it can be calculated by [15]

$$
D=\pi\left(\frac{h}{4 M_{\infty}}\right)^{2}\left(\frac{M_{2}-M_{1}}{\sqrt{t_{2}}-\sqrt{t_{1}}}\right)^{2},
$$

where $t_{2}$ and $t_{1}$ are arbitrary times selected along the linear portion of the curve, and $M_{1}$ and $M_{2}$ are the corresponding amount of absorbed moistures, respectively.

Moreover, d'Almeida et al. [18] reported that the following equation would better fit the experimental data when fiberglass pipes were tested,

$$
\frac{M_{\%}}{M_{\infty}}=\tanh \left(\frac{4}{h} \sqrt{\frac{D t}{\pi}}\right) .
$$

It has been shown $[18,19]$ that moisture-induced degradation of the fiber-matrix interface could significantly reduce the stiffness of the FRP pipes under bending, shear, and compression loading conditions, while the tensile strength would not be as significantly affected. This is because debonded 
fiber/matrix interfaces act mainly as interlaminar cracks and, therefore, would induce less impact on the strength of the pipes, especially under tensile loading.

In this research, bending tests were conducted on perforated glass/epoxy specimens having a quarter tube configuration, and, through the experimental data, a model was developed by which the stiffness of the perforated GFRP structures could be predicted.

\section{Specimen Preparation}

The material used in this research was 7781 woven E-glass/ NB321 epoxy cross-ply prepreg produced by Newport (Irvin, $\mathrm{CA})$. The tensile modulus and strength of the composite were determined experimentally in-house as $E_{\text {tensile }}=24.75 \mathrm{GPa}$, $S_{\text {tensile }}=370.5 \mathrm{MPa}$, respectively. The GFRP composite was selected due to its widespread usage in the applications where corrosion is of primary concern, as well as its relatively lower cost. Experimental specimens were fabricated in the configuration of one quarter of a perforated tube to study the influence of the hygrothermal effect on the composite under applied loading.

In order to fabricate the one-quarter tube with perforation, prepreg materials were first cut into $30 \mathrm{~mm}$-wide tapes (with a $3 \mathrm{~mm}$ thickness), and then they were laid on a steel mandrel in $\pm 45^{\circ}$ orientation, leaving $2 \mathrm{~mm}$ space among the tapes to create the perforated region. Figure 1 shows the representative volume's schematic used to form the geometry and the manufactured specimen, respectively. The final geometry was a quarter of a $250 \mathrm{~mm}$-long tube with a $150 \mathrm{~mm}$ diameter having $2 \times 2 \mathrm{~mm}^{2}$ perforations.

The layup sequence of all specimens was $\left[ \pm 45^{\circ}\right]_{4}$, and the curing process was carried out according to the vendor's instruction, that is, curing at $135^{\circ} \mathrm{C}$ for $2 \mathrm{hrs}$ and subsequently cooled down to the room temperature. The specimens were then trimmed and prepared for the experiment. The specimens' thickness was in the range of $2.7-3.2 \mathrm{~mm}$. The initial weight of each specimen was recorded for the subsequent moisture absorption studies. The fiber content of each specimen was also determined according to ASTM D3171-09 [20]; the average fiber content was at $55 \%$ by weight.

\section{Test Procedure}

The aging scenario adopted in this study is summarized in Table 1. Specimens were put in a controlled environmental chamber and aged at $60 \%$ humidity at temperatures of 40,60 , and $80^{\circ} \mathrm{C}$ ( 3 specimens tested at each temperature). The temperatures were chosen such that they were below the glass transition temperature of material (which was $150^{\circ} \mathrm{C}$ ). The saturation times for the specimens at various temperatures are also noted in Table 1. During the aging process, the moisture absorption percentile and its rate were measured in accordance to ASTM D5229 standard [21]. In our experiments, the saturation point was established as the stage when the change in the measured moisture content of the material

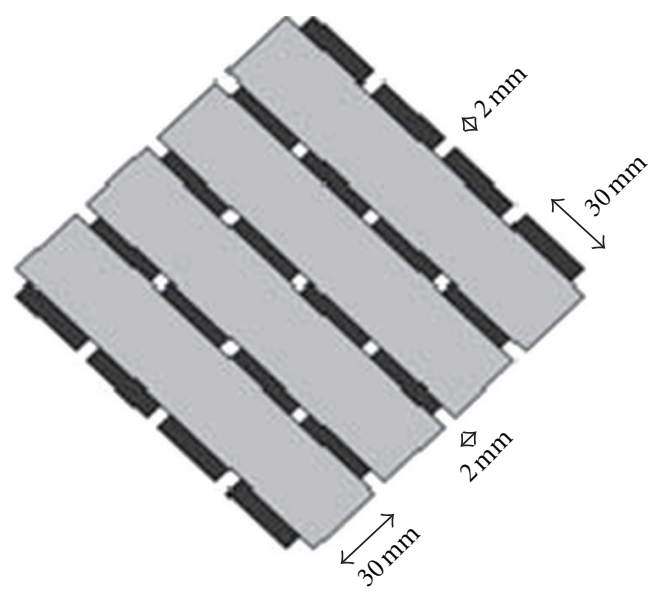

Figure 1: Representative volume used to fabricate the specimens.

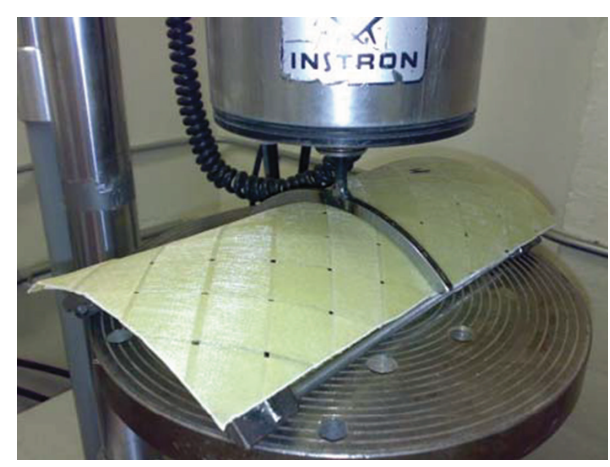

FIGURE 2: Three-point bending test setup.

TABLE 1: The aging scenarios.

\begin{tabular}{lccc}
\hline Environment & $\begin{array}{c}\text { Aging } \\
\text { temperature }\left({ }^{\circ} \mathrm{C}\right)\end{array}$ & $\begin{array}{c}\text { Number of } \\
\text { specimens }\end{array}$ & $\begin{array}{c}\text { Saturation } \\
\text { time (days) }\end{array}$ \\
\hline All specimens at & 40 & 3 & 55 \\
$60 \%$ moisture & 60 & 3 & 38 \\
content & 80 & 3 & 30 \\
\hline
\end{tabular}

at the selected interval was less than $0.01 \%$ with respect to the previously measured moisture content. After reaching the saturated conditions, the specimens were removed and the bending tests were conducted on the aged specimens and the reference virgin specimens, which were not exposed to temperature and humidity.

The supporting jig (frame) and loading jig, conformed to the exact shape of the specimens, are shown in Figure 2. The specimens were supported at their ends, on $9.5 \mathrm{~mm}$ diameter bars, and were loaded to failure by a MTS universal testing machine, equipped with an Instron $8500+$ electronic controller. The tests were conducted under displacementcontrolled condition, with a loading rate of $1.0 \mathrm{~mm} / \mathrm{min}$, at room temperature.

Subsequently, the fracture surfaces of the specimens were analyzed by scanning electron microscope (SEM) to further 
characterize the influence of the combined moisture/temperature on the materials.

\section{Experimental Results and Discussion}

5.1. Moisture Absorption Behavior. Moisture absorption percentage was calculated using the following equation and is presented as a function of square root of the exposure time:

$$
M_{t}=\frac{m-m_{0}}{m_{0}} 100 \%
$$

where $M_{t}$ is the percent moisture content at time $t, m_{0}$ is the weight of the specimen at its dry stage, and $m$ is the specimen weight at time $t$.

Figure 3 shows the variation in weight gain (i.e., moisture absorption) as a function of the square root of exposure time for all specimens. In this figure, solid symbols, solid line, and dashed line depict the experimental results, the results obtained using the hyperbolic tangent method (i.e., (3)), and those obtained by Fick's solution (obtained by (1a) and (1b)), respectively. As seen the Fickian model can better describe the moisture absorption response at the lower temperature aging condition, but at the high temperatures, the hyperbolic tangent model (i.e., (3)) could provide better prediction. It is postulated that the assumption of equal values for $D_{x}, D_{y}$, and $D_{z}$ used in these models would be a cause for the observed discrepancy. It is believed that these values would not be equal in the case of perforated tubular configuration; as a result, their variation as a function of temperature would also be different. Despite this fact, Fick's solution succeeded in predicting the results at the lower temperature, while hyperbolic tangent model could more accurately predict the absorption behavior at the higher temperature.

Comparison of the variation in the rate of moisture absorption at different aging temperatures (illustrated in Figure 4) reveals that when a longitudinal section of a perforated pipe was exposed to humidity, the increase in the exposure temperature from $40^{\circ} \mathrm{C}$ to $80^{\circ} \mathrm{C}$ increased the moisture absorption at saturated condition from $45 \%$ to $68 \%$, respectively. Moreover, the diffusion coefficient, $D$, which represents the slope of the linear portion of the curves of the perforated specimen, increased from 0.16 to $0.35 \mathrm{~mm}^{2} /$ day, respectively, when aged at the noted temperatures. In comparison, d'Almeida et al. [18] have reported $D$ as $0.57 \mathrm{~mm}^{2} /$ day for their aged pipe specimens, and De La Osa et al. [22] have reported GFRP's diffusion coefficients at different temperatures (i.e., 20,40 , and $60^{\circ} \mathrm{C}$ ), as $0.16,0.47$, and $0.97 \mathrm{~mm}^{2} /$ day for temperatures respectively. Our results are therefore in reasonable agreement with the reported experimental results.

5.2. Mechanical Characterization. Three-point bending tests were conducted on the specimens after aging. Figure 5 illustrates the typical damage initiation and growth in the specimens, when subjected to the bending test. In all specimens the damage occurred near the load line, and the crack propagated along the tape boundary through the perforations.

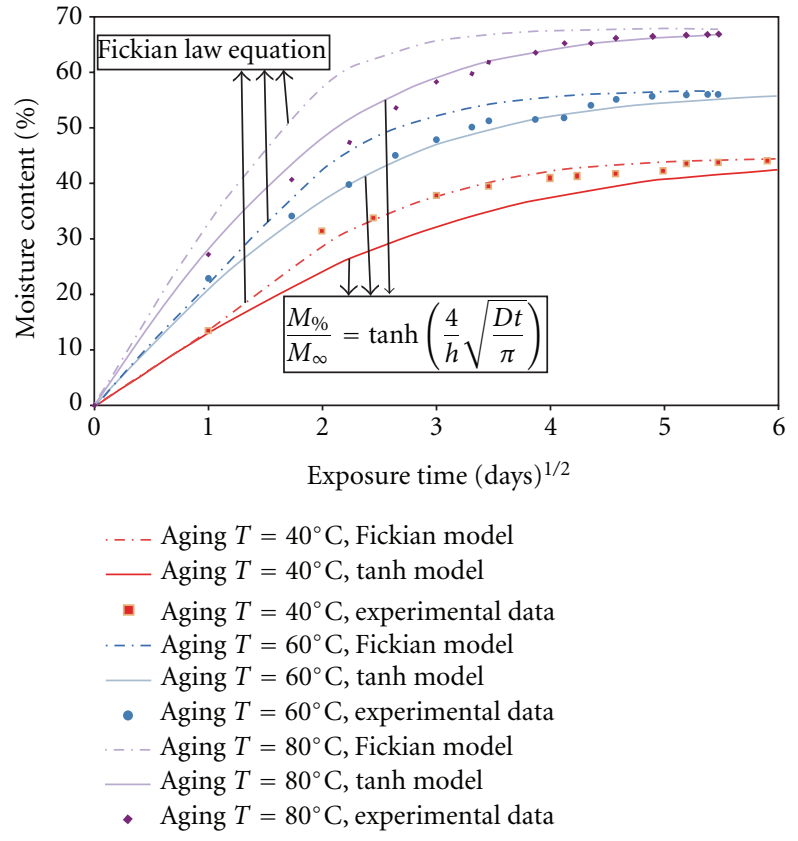

Figure 3: Moisture absorption of the specimens aged at $40^{\circ} \mathrm{C}, 60^{\circ} \mathrm{C}$, and $80^{\circ} \mathrm{C}$ temperature (humidity $=60 \%$ ).

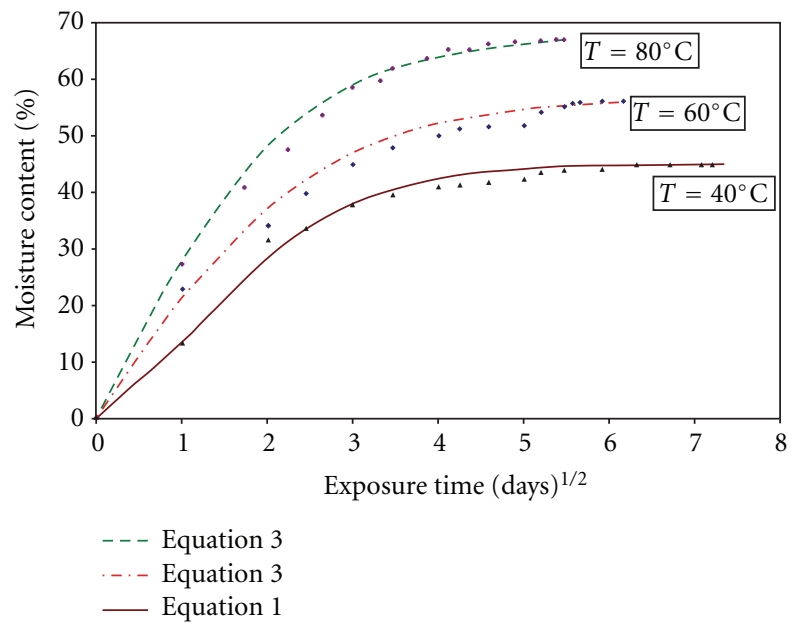

FIGURE 4: Average moisture absorption in different aging condition (humidity $=60 \%$ ). (solid lines represent the best fit lines obtained by the noted respective equations).

The bending tests' results have also been summarized in Table 2. It was observed that the increase in the aging temperature decreased the failure load, stiffness, and the maximum midspan displacement of the specimens. As seen in Figure 6, the trace of the bending curves for all test specimens was linear up to the fracture point, which reflects the brittle behavior of this composite component. The slope of the load-displacement curves reflects the stiffness of the perforated composite structure under bending. Figure 7 shows that with increasing the aging temperature and hence the diffusion rate and the resulting moisture content, the flexural 
TABLE 2: Bending test results for specimens aged at various temperatures (humidity $60 \%$ ).

\begin{tabular}{lcccc}
\hline Specimen/condition & Failure force $(\mathrm{N})^{*}$ & Maximum displacement $(\mathrm{mm})$ & Stiffness, K $(\mathrm{N} / \mathrm{mm})^{*}$ & Standard deviation \\
\hline $\mathrm{R}-01 /$ original & 176.05 & 2.2 & 82.5 & 0.104 \\
$\mathrm{H} 4 / T=40^{\circ} \mathrm{C}$ & 153.16 & 1.9 & 80.3 & 0.102 \\
$\mathrm{H} 6 / T=60^{\circ} \mathrm{C}$ & 139.08 & 1.8 & 78.2 & 0.104 \\
$\mathrm{H} 8 / T=80^{\circ} \mathrm{C}$ & 123.24 & 1.6 & 76.6 & 0.106 \\
\hline
\end{tabular}

The reported data are the mean values of 3 results for each category.

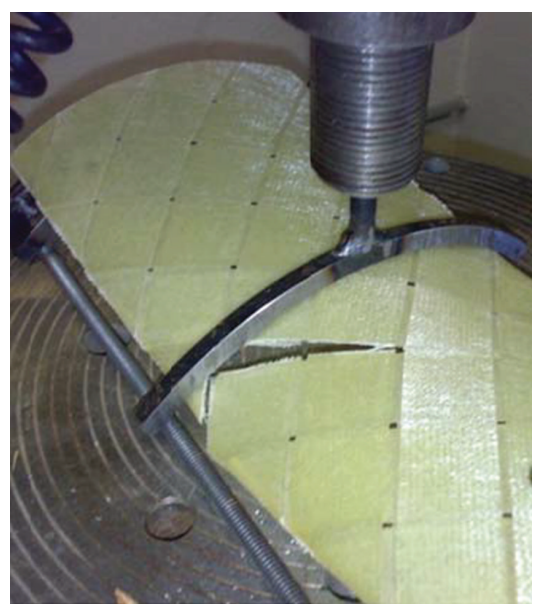

FIGURE 5: Failure mode observed as a result of the bending tests.

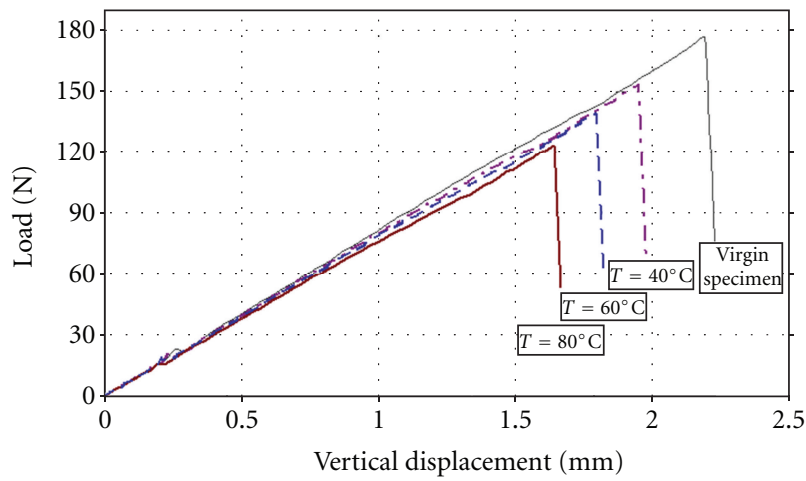

Figure 6: Plot of the average load versus displacement (each curve is the average of 3 specimens) for the specimens conditioned at different temperatures at $60 \%$ humidity.

stiffness of this perforated material decreased as much as $8.5 \%$. In the figure, the dot symbols represent the experimental results, and the dashed line is the least-square fitted line to the experimental data.

Noting the above results, it can be concluded that the flexural stiffness of a perforated pipe could be markedly affected by the diffusion rate and aging temperature. In consideration of the fact that according to (1a), (1b) the moisture content changes exponentially as a function of the diffusion coefficient and that the diffusion coefficient changes as a function of the aging temperature (see also Figure 4), a simple model is developed and proposed by which the change in the stiffness of a GFRP specimen, aged in humidity at

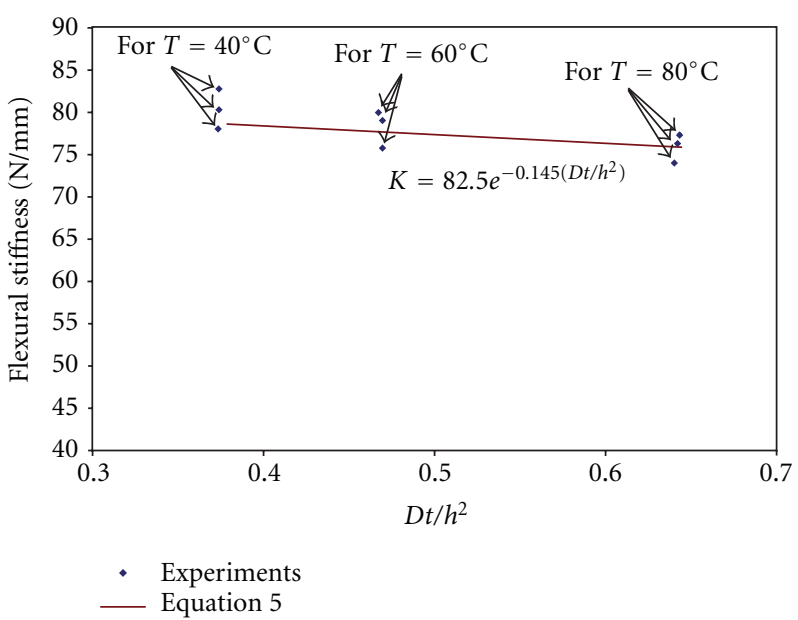

FIGURE 7: Variation of the flexural stiffness as a function of diffusion coefficient and aging temperatures for specimens aged at various temperatures in $60 \%$ humidity.

elevated temperature, is related to the influencing variables (i.e., the environmental parameters (i.e., the aging temperature and humidity), geometrical factors, and the physical and mechanical properties). The following equation represents the semiempirical exponential function:

$$
K_{a}=K_{u a} \times \exp \left(-0.145 \times\left(\frac{D t}{h^{2}}\right)\right),
$$

where $K_{a}$ is the flexural stiffness of the aged structure (in $\mathrm{N} / \mathrm{mm}$ ) and $K_{u a}$ is the flexural stiffness of the unaged material (in N/mm) at time $t=0 \mathrm{sec}$. Before the material is exposed to moisture, $D$ is the diffusion coefficient (in $\mathrm{mm}^{2}$ / day) and $D t / h^{2}$ is a non-dimensional parameter.

\section{SEM Analysis}

As stated earlier, to gain more insight into the physical effect of the moisture diffusion, scanning electron microscopy (SEM) was conducted on the fracture surfaces. Figure 8 shows the fracture surfaces of the glass/epoxy structure before and after the moisture immersion at $40^{\circ} \mathrm{C}$ and $80^{\circ} \mathrm{C}$ at $60 \%$ humidity. From the SEM-generated images one can observe that in the case of the virgin material (i.e., material that was not exposed to moisture and high temperature), good adhesion of resin to fibers is evident by the presence of large resin clusters; even after the fracture, the least amount of relative debonding is observed between the fibers and 


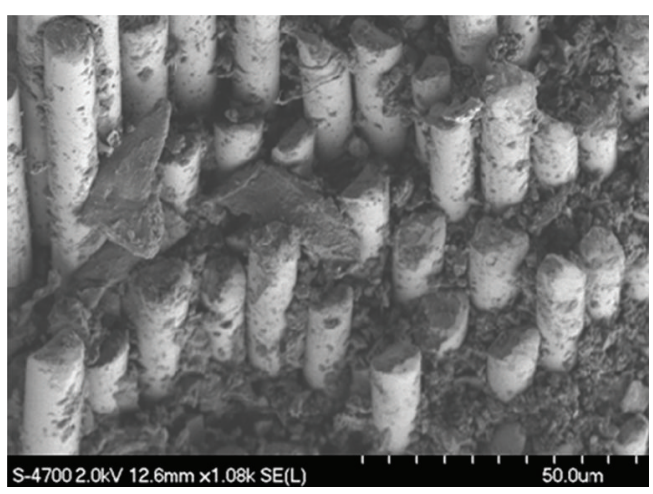

(a) Virgin

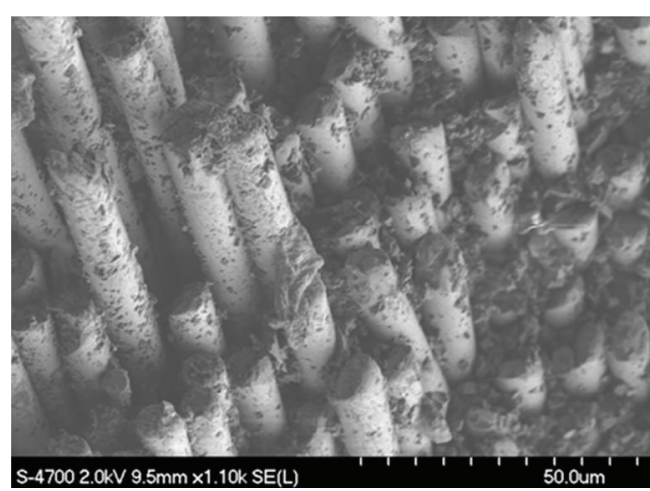

(b) at $40^{\circ} \mathrm{C}$

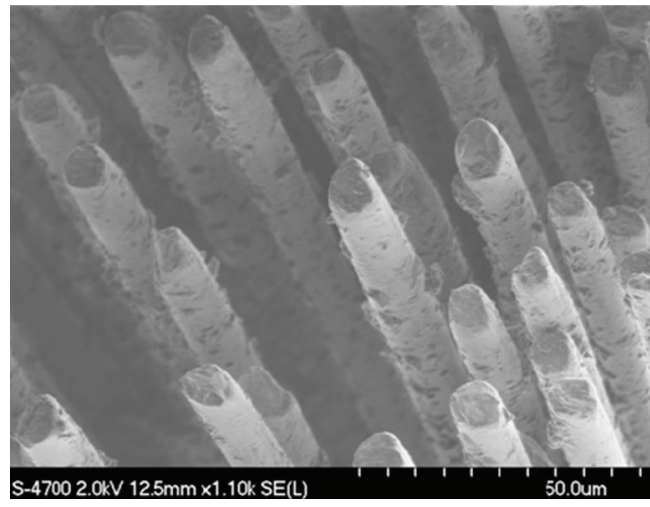

(c) at $80^{\circ} \mathrm{C}$

FIGURE 8: Comparison of the failure surfaces of unaged (virgin) perforated GFRP specimens and aged specimens at various temperatures (at $60 \%$ humidity).

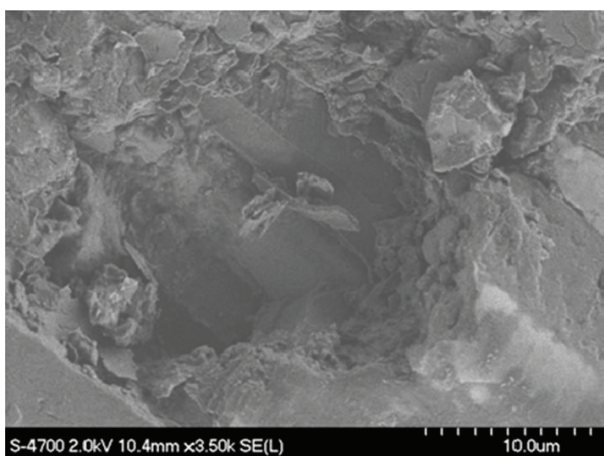

(a)

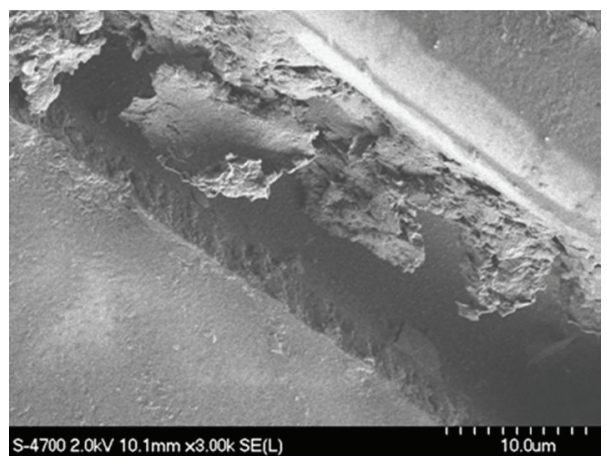

(b)

FIGURE 9: SEM image showing typical (a) voids and (b) cracks in the matrix of the perforated GFRP specimen aged in humidity at $80^{\circ} \mathrm{C}$.

matrix (Figure $8(\mathrm{a})$ ). This confirms the existence of a strong bond at the fiber and the matrix interface in the virgin specimens. However, with exposure to humidity and increasing temperature, the interface bond is degraded. This is demonstrated by decrease in the volume of the resin surrounding the fibers. Comparison of Figures 8(a) and 8(b), and then Figures 8(a) and 8(c) reveals that there is less decrease in the resin content in the specimen aged at $40^{\circ} \mathrm{C}$, while the resin degradation is much more pronounced in the specimen aged at $80^{\circ} \mathrm{C}$ (see Figures $8(\mathrm{~b})$ and $8(\mathrm{c})$ ).
Ingress of moisture into the matrix causes the matrix to swell, and the fiber/matrix interface tends to debond. In the presence of elevated temperature, the water molecules ingress into the voids in the matrix, and as the molecules' temperature is increased, their volume increases, thereby creating stress concentration and subsequently cracking the matrix [15]. The microscopic observation of our aged specimens revealed the presence of void content and cracks in the matrix of the specimens subjected to humidity and high temperature (see Figure 9). 


\section{Conclusions}

A short-term aging experimental investigation was conducted on curved perforated GFRP composite specimens, by which the effect of thermal variation on the moisture absorption kinetics and on the flexural stiffness of the GFRP specimens was investigated. The findings of this study can be summarized as follows.

Fick's model could describe the moisture absorption rate of the perforated GFRP specimens that were aged at relatively low temperatures, while the hyperbolic tangent model produced better predictions for the specimens conditioned at higher temperatures.

Moisture causes degradation in the resin matrix and in turn reduces the bending stiffness of the structures made of composite materials. As it is also known that Fick's model assumes that the moisture content varies exponentially as a function of diffusion coefficient and that the diffusion coefficient also changes as a function of the aging temperature. In concert with Fick's model, a simple semiempirical model was proposed; by this model one can predict the degradation in GFRP, when exposed to $60 \%$ humidity and various elevated temperatures, as a function of diffusion rate of the material and the exposure (conditioning) time.

Moreover, the increase in the temperature degraded the interface between the fibers and the matrix. The SEM analysis evidenced a dependency of the strength of GFRP to the reduction in the fiber/resin interfacial strength, through reducing the stress transfer in the GFRP.

An important concluding outcome of the investigation is that when perforated GFRP tubes are used to form liners in horizontal oil well applications, the influence of moisture/ temperature must be carefully considered and the design limits be adjusted accordingly.

\section{Acknowledgment}

The financial support of the Natural Sciences and Engineering Council of Canada (NSERC) in support of this work is gratefully acknowledged.

\section{References}

[1] C. L. Schutte, "Environmental durability of glass-fiber composites," Materials Science and Engineering R, vol. 13, no. 7, pp. 265-323, 1994.

[2] G. Alawsi, S. Aldajah, and S. A. Rahmaan, "Impact of humidity on the durability of E-glass/polymer composites," Materials and Design, vol. 30, no. 7, pp. 2506-2512, 2009.

[3] F. Ellyin and C. Rohrbacher, "Effect of aqueous environment and temperature on glass-fibre epoxy resin composites," Journal of Reinforced Plastics and Composites, vol. 19, no. 17, pp. 1405-1427, 2000.

[4] D. Perreux and C. Suri, "A study of the coupling between the phenomena of water absorption and damage in glass/epoxy composite pipes," Composites Science and Technology, vol. 57, no. 9-10, pp. 1403-1413, 1997.

[5] G. Sala, "Composite degradation due to fluid absorption," Composites, B, vol. 31, no. 5, pp. 357-373, 2000.
[6] B. F. Boukhoulda, E. Adda-Bedia, and K. Madani, "The effect of fiber orientation angle in composite materials on moisture absorption and material degradation after hygrothermal ageing," Composite Structures, vol. 74, no. 4, pp. 406-418, 2006.

[7] L. R. Bao and A. F. Yee, "Moisture diffusion and hygrothermal aging in bismaleimide matrix carbon fiber composites: part II-woven and hybrid composites," Composites Science and Technology, vol. 62, no. 16, pp. 2111-2119, 2002.

[8] M. Assarar, D. Scida, A. El Mahi, C. Poilâne, and R. Ayad, "Influence of water ageing on mechanical properties and damage events of two reinforced composite materials: flax-fibres and glass-fibres," Materials and Design, vol. 32, no. 2, pp. 788$795,2011$.

[9] G. Huang and H. Sun, "Effect of water absorption on the mechanical properties of glass/polyester composites," Materials and Design, vol. 28, no. 5, pp. 1647-1650, 2007.

[10] A. S. Maxwell, W. R. Broughton, G. Dean, and G. D. Sims, "Review of accelerated aging methods and lifetime prediction techniques for polymeric materials," NLP Report DEPC MPR 016, 2005.

[11] P. K. Aditya and P. K. Sinha, "Moisture diffusion in variously shaped fibre reinforced composites," Computers and Structures, vol. 59, no. 1, pp. 157-166, 1996.

[12] K. Imielińska and L. Guillaumat, "The effect of water immersion ageing on low-velocity impact behaviour of woven aramid-glass fibre/epoxy composites," Composites Science and Technology, vol. 64, no. 13-14, pp. 2271-2278, 2004.

[13] D. Scida, Z. Aboura, and M. L. Benzeggagh, "The effect of ageing on the damage events in woven-fibre composite materials under different loading conditions," Composites Science and Technology, vol. 62, no. 4, pp. 551-557, 2002.

[14] A. Nakai, S. Ikegaki, H. Hamada, and N. Takeda, "Degradation of briaded composites in hot water," Composites Science and Technology, vol. 60, no. 3, pp. 325-331, 2000.

[15] F. Ellyin and R. Maser, "Environmental effects on the mechanical properties of glass-fiber epoxy composite tubular specimens," Composites Science and Technology, vol. 64, no. 12, pp. 1863-1874, 2004.

[16] K. Berketis, D. Tzetzis, and P. J. Hogg, "The influence of long term water immersion ageing on impact damage behaviour and residual compression strength of glass fibre reinforced polymer (GFRP)," Materials and Design, vol. 29, no. 7, pp. 1300-1310, 2008.

[17] G. S. Springer, Environmental Effects on Composite Materials, vol. 3, Chapter 1, Technomic, Lancaster, Pa, USA, 1981.

[18] J. R. M. d'Almeida, R. C. de Almeida, and W. R. de Lima, "Effect of water absorption of the mechanical behavior of fiberglass pipes used for offshore service waters," Composite Structures, vol. 83, no. 2, pp. 221-225, 2008.

[19] M. Akay, S. Kong Ah Mun, and A. Stanley, "Influence of moisture on the thermal and mechanical properties of autoclaved and oven-cured Kevlar-49/epoxy laminates," Composites Science and Technology, vol. 57, no. 5, pp. 565-571, 1997.

[20] ASTM D3171-09, Standard Test Methods for Constituent Content of Composite Materials.

[21] ASTM D5229, Standard Test Method for Moisture Absorption Properties and Equilibrium Conditioning of Polymer Matrix Composite Materials.

[22] O. De La Osa, V. Alvarez, and A. Avazquez, "Effect of hygrothermal history on water and mechanical properties of glass/ vinylester composites," Journal of Composite Materials, vol. 40, no. 22, pp. 2009-2023, 2006. 

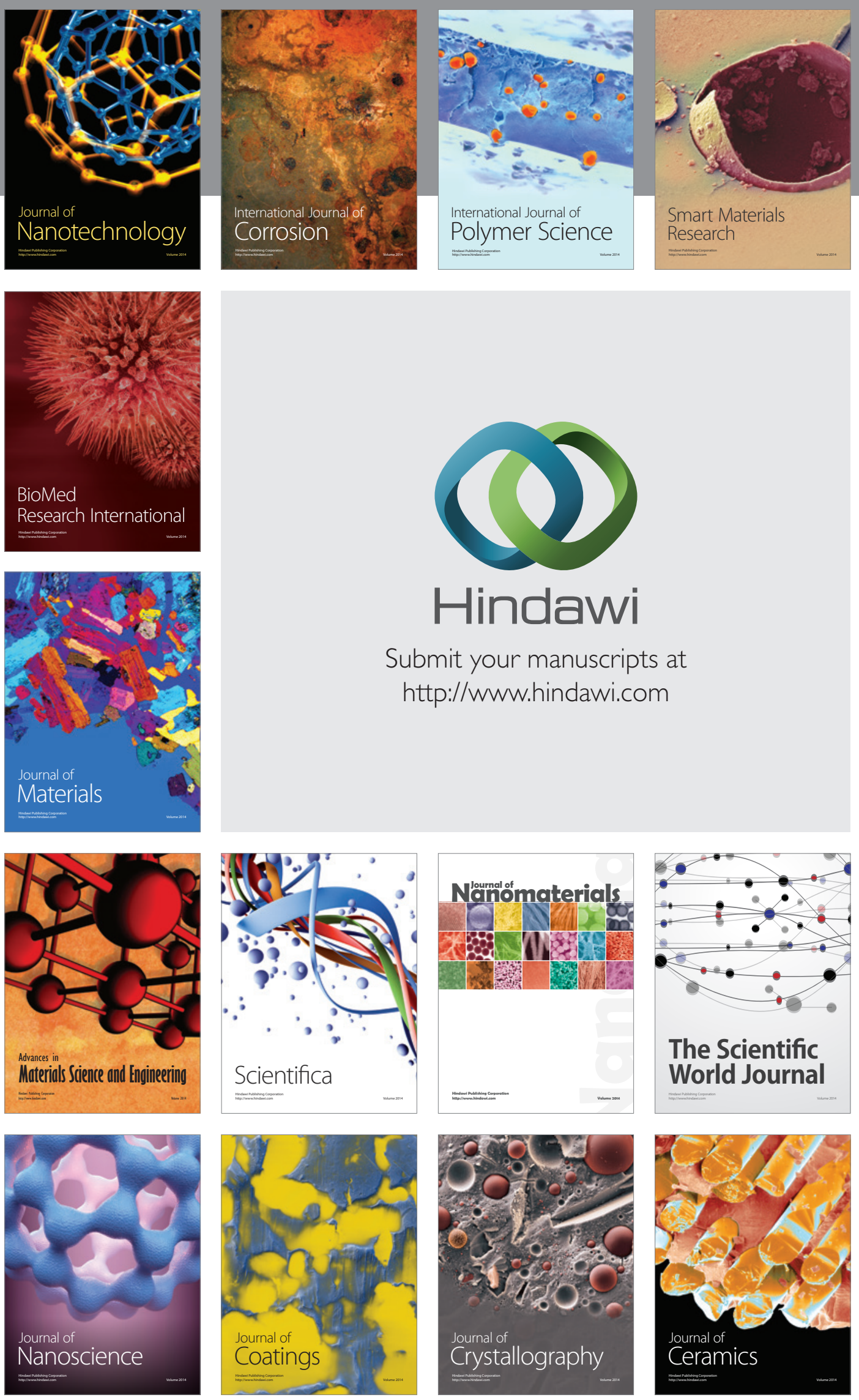

The Scientific World Journal

Submit your manuscripts at

http://www.hindawi.com

\section{World Journal}

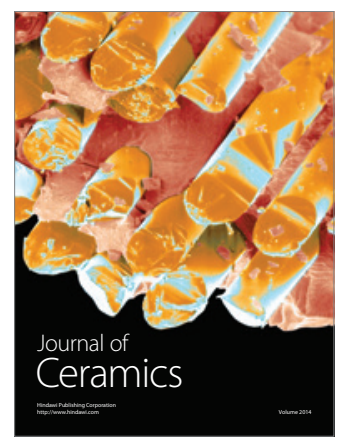

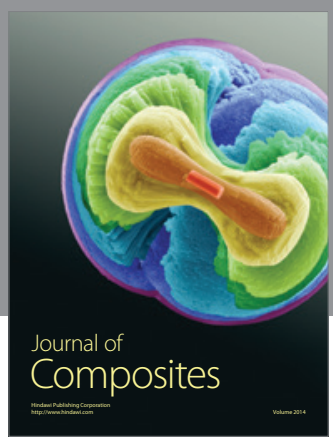
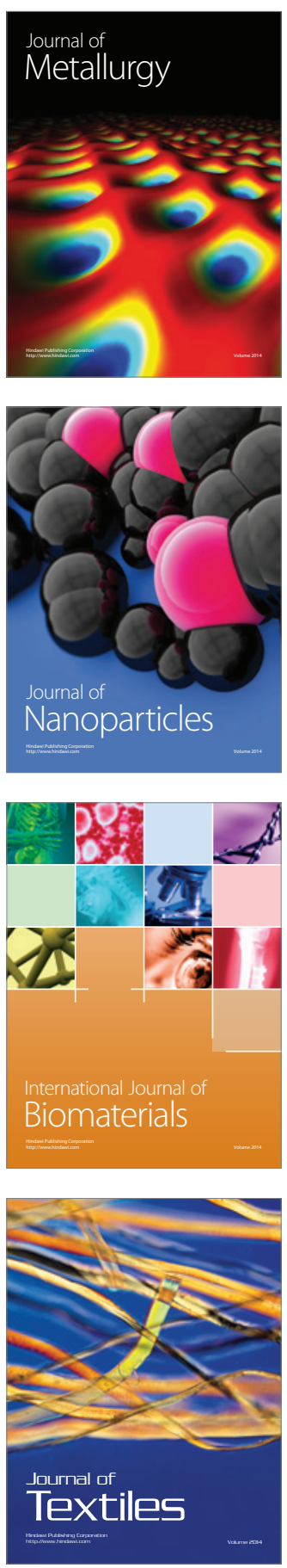